\title{
Crenças linguísticas que norteiam a escolha da língua espanhola para o ENEM
}

\author{
Linguistic beliefs that guide the choice of the Spanish language for the ENEM
}

Mitos y creencias son las luchas heroicas de comprender la verdad en el mundo.
(Ansel Adams)

\author{
Poliana de Oliveira Santos ${ }^{*}$ \\ Universidade Federal do Sul e Sudeste do Pará \\ Marabá, Pará, Brasil \\ Eliane Machado Soares** \\ Universidade Federal do Sul e Sudeste do Pará \\ Marabá, Pará, Brasil
}

\begin{abstract}
Resumo: O presente artigo objetiva investigar as crenças linguísticas que norteiam a escolha da língua espanhola como língua estrangeira para o ENEM bem como quais destas são predominantes em relação a dada escolha. Como princípios teóricos, as bases são os estudos sociolinguísticos, especificamente os que se referem a crenças linguísticas. São analisadas as bases propostas pelos documentos oficiais para o ensino de língua estrangeira: LDB, Parâmetros Curriculares, OCEM (orientações curriculares para o ensino médio). O corpus da pesquisa é constituído de dados coletados na cidade de Jacundá-PA, com 20 informantes (19 alunos do Ensino Médio $-3^{\circ}$ ano, 1 professora - habilitada em Inglês e Espanhol) da Escola Arte de Educar de Jacundá (instituição privada), a partir de entrevistas gravadas e, posteriormente, transcritas. Utilizou-se como instrumento um questionário contendo cinco perguntas para avaliar e alcançar o objetivo inicialmente proposto.
\end{abstract}

Palavras-chave: Crenças linguísticas. Ensino de língua espanhola. ENEM.

\begin{abstract}
This paper aims to investigate the linguistic beliefs that guide the choice of Spanish as a foreign language for the ENEM, as well as elect which of these are predominant in relation to given choice. As theoretical principles, the basis is Sociolinguistic studies, specifically those that refer to linguistic beliefs. We analyse the foundations proposed by official documents in foreign language teaching: parameters OCEM curriculum (curriculum guidelines for middle school). The corpus of this research consists of data collected in the city of Jacundá-Pará, with 20 informants (19 high school students - 3rd year, 1 teacher - enabled in English and Spanish) of the Escola Arte de Educar de Jacundá (institution private), through taped interviews and subsequently transcribed. WE used as an instrument a questionnaire containing five questions to evaluate and to achieve the goal initially proposed.
\end{abstract}

Keywords: Linguistic beliefs. Spanish language education. ENEM.

*Mestranda do Programa de Pós-Graduação em Letras - POSLET - Universidade Federal do Sul e Sudeste do Pará, Marabá, Pará, Brasil. E-mail: polianadeoliveirasantos795@gmail.com.

${ }^{* *}$ Professora do Programa de Pós-Graduação em Letras - POSLET - Universidade Federal do Sul e Sudeste do Pará, Marabá, Pará, Brasil. E-mail: eliane@unifesspa.edu.br. 


\section{INTRODUÇÃO}

Quando pensamos e trabalhamos com o ensino de língua espanhola a falantes brasileiros, na realidade assumimos um desafio que vai além do compromisso social e educacional, já que nos deparamos com alguns problemas que reforçam a desvalorização atribuídos ao ensino de línguas estrangeiras no que diz respeito a sua inserção no componente curricular, ademais da presença de crenças que permeiam e estão arraigadas ao pensamento dos aprendizes. No que concerne ao componente curricular, as escolas particulares, geralmente, optam por disponibilizar o ensino de duas línguas estrangeiras desde o Fundamental II ao Ensino Médio, o inglês e o espanhol, assim os alunos têm a oportunidade de preparar-se em ambas para o Exame Nacional do Ensino Médio (ENEM) e, consequentemente, escolher uma destas. Assim, analisaremos, refletiremos e discutiremos sobre as crenças linguísticas presentes na aprendizagem de língua espanhola que direcionam a escolha de tal disciplina para o ENEM (Exame Nacional do Ensino Médio).

Dividido este artigo em três seções, apresentamos: na primeira, propostas e reflexões a respeito da importância da Sociolinguística e seu status de campo investigativo no que concerne aos estudos linguísticos, no âmbito de crenças; na segunda seção, um breve histórico do ensino de língua espanhola no Brasil; na terceira, a metodologia e a análise com os resultados da pesquisa.

\section{OS ESTUDOS LÍNGUISTICOS E A SOCIOLÍNGUISTICA: PERSPECTIVAS GERAIS E CONTRIBUIÇÕES PARA OS ESTUDOS DE CRENÇAS}

A linguística moderna consolida-se como ciência em meados do século XX. Até então, vários estudiosos debruçaram-se para o intento de explicar e entender o que é a língua, mas foi a partir dos estudos de Ferdinand de Saussure e o interesse em definir aspectos importantes para a elaboração de um modelo investigativo de base estruturalista que esta se firmou. Os estudos delimitavam o campo da ciência com ênfase apenas para a estrutura abstrata e com uma nítida separação no que concerne à língua em seu uso social. Desta forma, os estudos saussurianos constituem o ponto de partida para seus seguidores na tentativa de abordar o novo campo investigativo considerando a língua em si e por si mesma. Entretanto um de seus discípulos, Antoine Meillet (1866-1936), filiando-se aos ideais do sociólogo Émile Durkheim, propunha a ideia de que esta língua era um fato social, pois, para ele, "ao separar a variação linguística das condições externas de que ela depende, Ferdinand de Saussure a priva de realidade; ele a reduz a uma abstração que é necessariamente inexplicável” (MEILLET, 1965, p. 230).

Nesse sentido, enquanto Saussure opõe a linguística interna à linguística externa, Meillet as associa, e estudar a língua deveria estar centralizado dentro da teoria linguística, em que a língua é fato social e um sistema complexo que tudo contém, ademais deveria dar conta dessa dupla determinação (forma $\times$ social). Surge assim, a partir da linguística 
moderna, de um lado um discurso estruturalista com bases nos estudos saussurianos, essencialmente enraizado na forma da língua, e outro oposto, Antoine Meillet, que insiste na língua e sua função entrelaçada ao social. Diante disso, Meillet torna-se um precursor que mais tarde terá uma ampliação de suas propostas, já que, em 1964, pesquisadores apresentaram comunicações em que tratavam sobre um novo âmbito investigativo, a Sociolinguística, que teve como um de seus participantes e impulsionadores William Labov.

O linguista americano, em 1966, publica um estudo sobre a estratificação social do /r/ nas grandes lojas de departamento nova-iorquinas, o texto aguça opiniões de que este tem traços de manifesto, pode-se percebê-lo como uma retomada das ideias de Meillet:

Para nós, nosso objeto de estudo é a estrutura e a evolução da linguagem no seio de contexto social formado pela comunidade linguística. Os assuntos considerados provêm do campo normalmente chamado 'linguística geral': fonologia, morfologia, sintaxe e semântica [...]. Se não fosse necessário destacar o contraste entre este trabalho e o estudo da linguagem fora de todo contexto social, eu diria de bom grado que se trata simplesmente de linguística. (LABOV, 1966, p. 258)

Assim, vemos que houve uma necessidade de entender melhor vários processos inerentes à língua, que vão além do ideal de forma. Destarte, pós século $\mathrm{XX}$, os principais estudos produzidos a partir dessa perspectiva se constroem pelos pressupostos da Sociolinguística, área recente, fixada na década de 1960 - que estuda a língua falada, observada, descrita e analisada em seu contexto social, e que tem como ponto de partida a comunidade linguística, que é representada por um conjunto de pessoas que interagem verbalmente e que compartilham um conjunto de normas com respeito aos usos linguísticos. Para Moreno Fernández (1998, p. 181), "uma das bases sobre as quais se assenta a atitude linguística é a consciência sociolinguística: os indivíduos forjam atitudes, quaisquer que sejam, porque têm consciência de uma série de fatos linguísticos e sociolinguísticos que referem a eles ou lhes afetam".

Neste sentido, entendemos a importância desse âmbito investigativo, e eis que surge um questionamento: afinal, o que são crenças e qual sua relação com o ensino de línguas? De acordo com (BARCELOS, 2001, p. 72), apesar de existirem vários conceitos para definir o termo crenças e de não apresentarem uma uniformidade, quando relacionadas à aprendizagem de línguas, podem ser conceituadas, de maneira geral, como juízos e ideias que alunos (e professores) têm a respeito dos processos de ensino e aprendizagem de línguas. Ainda de acordo com a autora, as crenças originam-se a partir de nossas experiências e na cultura e se ligam a um contexto, são pessoais e situacionais.

A princípio, acreditava-se que as crenças eram fixas, estáveis e distintas de conhecimento, porém, com várias investigações, percebeu-se que elas são dinâmicas, construídas no social, contextuais e mediadas pela experiência. Como diz Barcelos (2006, p. 19), "não estão dentro de nossas mentes como uma estrutura mental pronta e fixa, mas mudam e se desenvolve à medida que interagimos e modificamos nossas experiências e somos, ao mesmo tempo, modificados por elas". 
O termo antes tinha inúmeras definições. Pajares (1992) elenca alguns: atitudes, valores, julgamentos, axiomas, opiniões, ideologia etc. $\mathrm{O}$ autor ainda afirma que as crenças são um conceito complexo. Entretanto Barcelos (2001, p. 72) alerta-nos para diversos termos para um mesmo conceito, mas afirma que, para o âmbito do ensino de línguas. é cabível utilizar crenças, posto que:

O termo crenças é aqui favorecido, uma vez que concebemos o mesmo como inteiramente satisfatório para o nosso contexto de estudo, por envolver o dizer e o fazer dos sujeitos inseridos num contexto social micro (sala de aula, por exemplo) e macro (o aluno inserido em seu meio, atuando em um determinado grupo sócio culturalmente constituído). (BARCELOS, 2004 a, p. 148)

Percebe-se, dessa forma, que as crenças estão atreladas à construção da aprendizagem e que, na relação aluno $\mathrm{x}$ professor, se torna um terreno fértil, principalmente no que diz respeito ao ensino de línguas estrangeiras. Observa-se que as crenças, por agirem sobre o comportamento, influenciam a aquisição do conhecimento tanto de forma positiva quanto negativa, assumindo um papel fundamental na construção do aprendizado dos discentes.

\section{ENSINO DE LÍNGUA ESPANHOLA NO BRASIL}

A presença do Espanhol no Brasil pode ser identificada em vários momentos, uma delas é representada pelas primeiras viagens exploratórias realizadas por Cristóvão Colombo no período de 1494 e 1495 pela costa Sul-americana, para assessorar os reis da Espanha a respeito da delimitação estabelecida no Tratado de Tordesilhas. Por conseguinte, outro aspecto de relevância foi o fato de a Espanha ter sido assolada por uma grande crise econômica em meados do século XIX, o que trouxe uma aproximação com o Brasil por causa do fluxo imigratório, uma vez que houve uma necessidade de substituir a mão de obra escrava por mão de obra barata, principalmente para trabalhar nos grandes cafezais. Neste sentido, por possuir quase $75 \%$ de trabalhadores imigrantes, surge em São Paulo um dos centros de ensino de espanhol de maior importância de todo o país, o Colégio Miguel de Cervantes.

Em 1991, a partir do acordo assinado entre os países do MERCOSUL, tivemos um boom nos cursos de Espanhol em nosso país, posto que o contato pessoal e comercial estabelecido com a fronteira meridional com Paraguai, Argentina e Uruguai deu lugar ao surgimento desse mercado comum, além de surgir uma modalidade linguística de fronteira, o que fortaleceu mais esta relação. Desde então, o idioma está presente e buscando seu espaço.

A primeira regulamentação de ensino de línguas estrangeiras aparece na Lei 9394/96, de Diretrizes e Bases para a Educação Nacional (LDB), de 20 de novembro de 1996, que reconhece o ensino de língua estrangeira de forma obrigatória para o nível de ensino primário nos seguintes termos: "Na parte diversificada do currículo será incluído, obrigatoriamente, a partir da quinta série, o ensino de pelo menos uma língua estrangeira moderna, cuja escolha ficará a cargo da comunidade escolar, dentro das possibilidades da 
instituição" (Art. 26, $\left.\int 5^{\circ}\right)^{1}$. Para o Ensino Médio (15 a 18 anos) "será incluída uma língua estrangeira moderna, como disciplina obrigatória, escolhida pela comunidade escolar, e uma segunda, em caráter optativo, dentro das disponibilidades da instituição" (Art. 36, III) $)^{2}$.

A Lei $n^{\circ}$ 11.161, de 5 de agosto de 2005, é responsável pela segunda fase de crescimento do ensino da língua espanhola no Brasil, já que outorga em sete artigos a obrigatoriedade das escolas públicas e privadas de ofertar aos seus alunos o ensino da língua em questão.

Para o ensino médio, em 2006, a proposta das OCEM (Orientações Curriculares para o Ensino Médio) para o âmbito de Línguas Estrangeiras tem como objetivo:

retomar a reflexão sobre a função educacional do ensino de Línguas Estrangeiras no ensino médio e ressaltar a importância dessas; reafirmar a relevância da noção de cidadania e discutir a prática dessa noção no ensino de Línguas Estrangeiras; discutir o problema da exclusão no ensino em face de valores "globalizantes" e o sentimento de inclusão frequentemente aliado ao conhecimento de Línguas Estrangeiras; introduzir as teorias sobre a linguagem e as novas tecnologias (letramentos, multiletramentos, multimodalidade, hipertexto) e dar sugestões sobre a prática do ensino de Línguas Estrangeiras por meio dessas. (OCEM, 2006, p. 87)

As orientações de ensino de línguas, assim como os PCNs, já aguçavam essa importância:

Por não visar à aquisição de uma totalidade de linguagem, cultura e conhecimento, essa concepção de letramentos heterogêneos e "comunidades de prática" visa a formar um aprendiz capaz de compartilhar, recriar, recontextualizar e transformar, e não de reproduzir conhecimentos estanques. (OCEM, 2006, p. 108)

Nesse sentido vemos que o estudo de línguas é de grande importância para os aprendizes, é uma forma de desenvolver a competência intercultural e de obter conhecimentos que servirão de base para sua vida dentro e fora da escola.

\section{METODOLOGIA}

Para a elaboração da pesquisa foi utilizada uma abordagem de natureza quantiqualitativa, uma vez que o processo de construção, compreensão e interpretação dos dados foi feito de maneira descritiva e indutiva.

A escola pesquisada pertence à rede privada e está localizada na cidade de Jacundá - Pará. A escolha deste cenário ocorreu, principalmente, pelo fato de haver uma carência

\footnotetext{
${ }^{1}$ Este parágrafo foi revogado em redação dada pela Lei $\mathrm{n}^{\circ}$ 13.415, de 2017: "No currículo do ensino fundamental, a partir do sexto ano, será ofertada a língua inglesa. No currículo do ensino fundamental, a partir do sexto ano, será ofertada a língua inglesa".

${ }^{2}$ Os currículos do ensino médio incluirão, obrigatoriamente, o estudo da língua inglesa e poderão ofertar outras línguas estrangeiras, em caráter optativo, preferencialmente o espanhol, de acordo com a disponibilidade de oferta, locais e horários definidos pelos sistemas de ensino (Incluído pela Lei no 13.415 , de 2017).
} 
de ensino de língua espanhola em escolas públicas (para o ensino médio) e porque buscamos um grupo que tivesse o contato com línguas estrangeiras desde o $6^{\circ}$ ano do Ensino Fundamental (antiga $5^{\mathrm{a}}$ série). Outro fator diz respeito à escola em questão proporcionar a possibilidade de que os aprendizes estudem duas línguas estrangeiras no currículo, o Inglês e o Espanhol, elemento que corrobora e norteia na escolha da língua estrangeira para o ENEM ${ }^{3}$.

Os participantes envolvidos na pesquisa encontram-se divididos da seguinte forma: 20 informantes (19 alunos do Ensino Médio - $3^{\circ}$ ano, 1 professora - habilitada em Inglês e Espanhol). Os dados foram coletados através de entrevistas gravadas e, posteriormente, transcritas, utilizou-se como instrumento um questionário contendo cinco perguntas para avaliar e alcançar o objetivo inicialmente proposto:

a. O que é uma língua estrangeira?

b. Com quais línguas estrangeiras você tem contato e qual prefere?

c. Qual língua estrangeira você escolheu para o ENEM? Por quê?

d. Você acha importante ter línguas estrangeiras no componente curricular?

e. O que você acha importante desenvolver/aprender para se sair bem na prova de língua estrangeira do ENEM?

A metodologia da pesquisa estendeu-se por um período de três meses, sendo um mês para a observação e elaboração do questionário, seguido das entrevistas, e dois meses para a análise e interpretação dos dados.

\section{ANÁLISE E DISCUSSÃO DOS RESULTADOS}

Nesta seção, apresentamos as conclusões acerca dos objetivos propostos e das crenças dos participantes deste estudo frente à escolha da Língua Espanhola para o ENEM, explicitadas a seguir algumas perguntas e respostas do questionário da entrevista. Ressaltamos que tentamos fazer um esboço geral de alguns argumentos para enfim chegar à intenção final da pesquisa, mostrar o que leva os alunos a escolherem a Língua Espanhola para o ENEM, mediante a apresentação de suas crenças. Desta forma, os primeiros gráficos apenas reforçam e direcionam para tais convicções dos aprendizes.

As respostas dadas à primeira pergunta - "O que é uma língua estrangeira?" possibilitaram a elaboração do Gráfico 1:

\footnotetext{
3 O ENEM (Exame Nacional do Ensino Médio) é uma prova que tem como característica a transdisciplinaridade. O conceito de transdisciplinaridade consiste em formular questões que dependem do uso de duas ou mais disciplinas aprendidas no ensino médio para obter sua resposta. O novo modelo de prova do ENEM, utilizado desde outubro de 2009, conta com 180 questões e uma redação, 45 para quatro partes, excluindo a redação, realizado em dois dias, sendo a prova dividida em 5 partes (Linguagens, Matemática, Ciências da Natureza, Ciências Humanas e Redação).
} 


\section{Revista \\ das Letras}

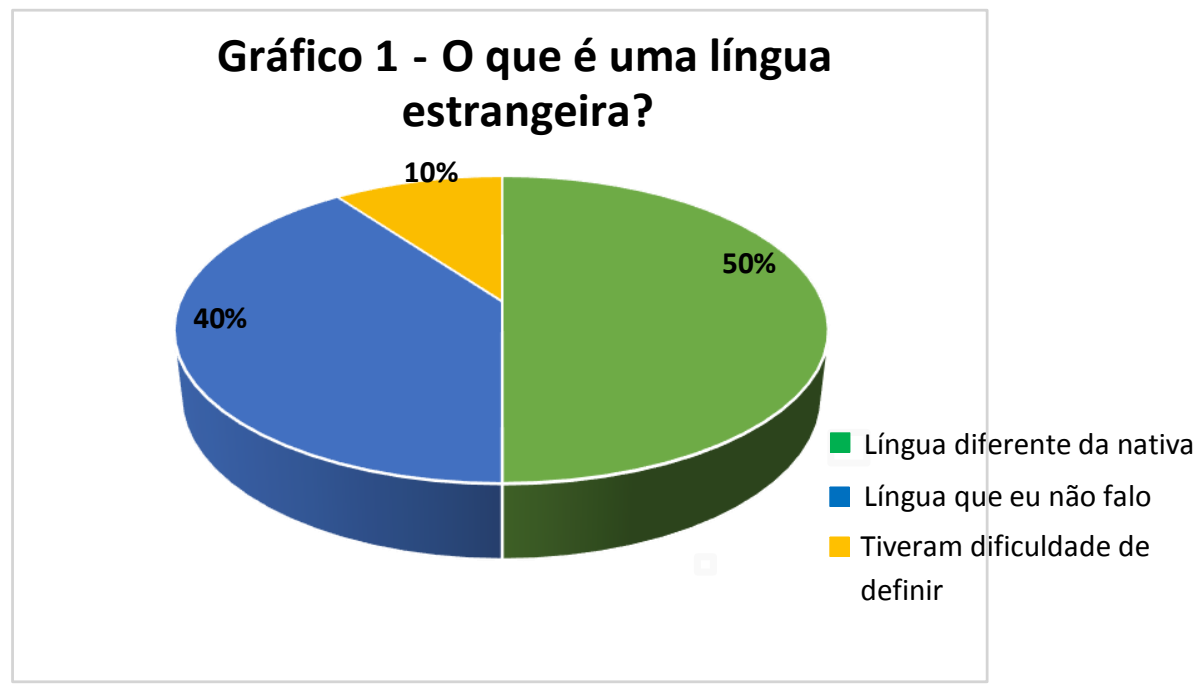

Merecem destaque as falas de alguns informantes, que assim expressaram:

Para mim lingua estrangeira é qualquer língua que não seja a nativa de um país... tipo... aqui no Brasil a gente fala Português, ai Inglês e Espanbol se trata como lingua estrangeira. (AM17)

Uma lingua que eu não falo no meu dia a dia, ou seja, a minha lingua natal... (BF16)

Sei lá! É uma língua diferente da minha língua materna, da qual eu cresci falando... (GF16)

É uma lingua diferente da nossa, que seria o Português. (PHM16)

Pra mim uma lingua estrangeira é muito essencial pra gente, a gente é brasileiro então precisamos aprender um pouco do Inglês e do Espanhol que são dos outros países. (VF16)

A partir dessas respostas, percebemos que alguns alunos, mesmo experimentando o estudo de línguas desde o ensino fundamental II, ainda não conseguem definir o que é uma língua estrangeira ${ }^{4}$ já outros percebem que é uma língua que não é a sua língua materna ${ }^{6}$, e consequentemente tem diferenças e estes a veem de maneira clara.

O Gráfico 2 foi gerado a partir da pergunta: "Você acha importante ter línguas estrangeiras no componente curricular"?

\footnotetext{
${ }^{4}$ Según el diccionario de términos clave de ELE: Lengua extranjera es la lengua que se aprende en una comunidad en la que no hay presencia mayoritaria de hablantes de esa lengua, es decir se trata de aquella lengua a la que el aprendiente no tiene acceso directo en su comunidad lingüística habitual. Lengua materna: es la lengua habitual en el seno de la familia, transmitida de generación en generación.
} 


\section{das Letras}

\section{Gráfico 2 - Você acha importante ter línguas estrangeiras no componente curricular"?}

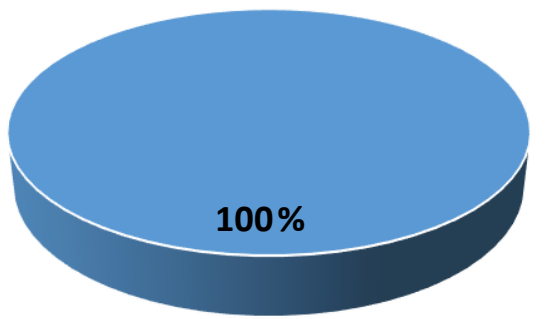

Para a segunda pergunta, destacam-se algumas respostas:

É uma forma de você ter uma base de outras linguas não só da sua, fora a parte que você estudando pelo menos o básico na escola e você querer, por exemplo, viajar, você vai ter um conhecimento para poder viajar... de poder se comunicar com cultura de outros paises. (HF16)

Eu acho sim porque 'tipo' o mercado de trabalho está mais voltado, aí.. 'tipo' se a pessoa vai fazer qualquer tipo de curso ela precisa de uma outra lingua(...) tipo o inglês que é uma língua universalizada e também a lingua espanhola, a América do Sul, quase toda fala Espanhol então acho que é importante. (AM17)

(...) para aprender mais, porque se você precisa sair dos seu país de origem saber se comunicar. (KF16)

Sim, porque hoje em dia no mercado de trabalho qualquer lugar que você vai trabalhar uma grande maioria exige que você saiba ou tenba noção de uma língua estrangeira [..] (BF16)

Sim, porque pode acontecer de fažer faculdade em um outro país, intercâmbios. (LF16)

Acho sim, porque por exemplo se você for um profissional pode te auxiliar tanto numa questão do curriculo, se precisar ir para fora é necessário. (NM17)

$\mathrm{Na}$ segunda pergunta, todos os alunos convergiram para a importância de termos no currículo escolar o ensino de línguas estrangeiras, o que é reforçado nas OCEM (2006, p. 92):

Desenvolver, com isso, a confiança do aprendiz, por meio de experiências bem sucedidas no uso de uma língua estrangeira, enfrentar os desafios cotidianos e sociais de viver, adaptandose, conforme necessário, a usos diversos da linguagem em ambientes diversos (sejam esses 


\section{Revista

em sua própria comunidade, cidade, estado, país ou fora desses).

E dizem os PCNs (2017, p. 93) que "ao se apropriar de uma língua, o aluno se apropria também dos bens culturais que ela engloba. Tais bens lhe permitirão acesso à informação em sentido amplo, bem como uma inserção social mais qualificada, da qual poderá beneficiar-se e sobre a qual poderá interferir".

Nesse sentido, apesar de 100\% dos alunos concordarem com a importância de inserção de línguas estrangeiras, as justificativas são diferentes, posto que $50 \%$ justifica relacionando a ideia de mercado de trabalho e $50 \%$ a ideia de viagens. Isso revela que esse aluno, apesar de uma "imaturidade" para com os estudos, reconhece que todo conhecimento é relevante e tem uma importância social para suas vidas.

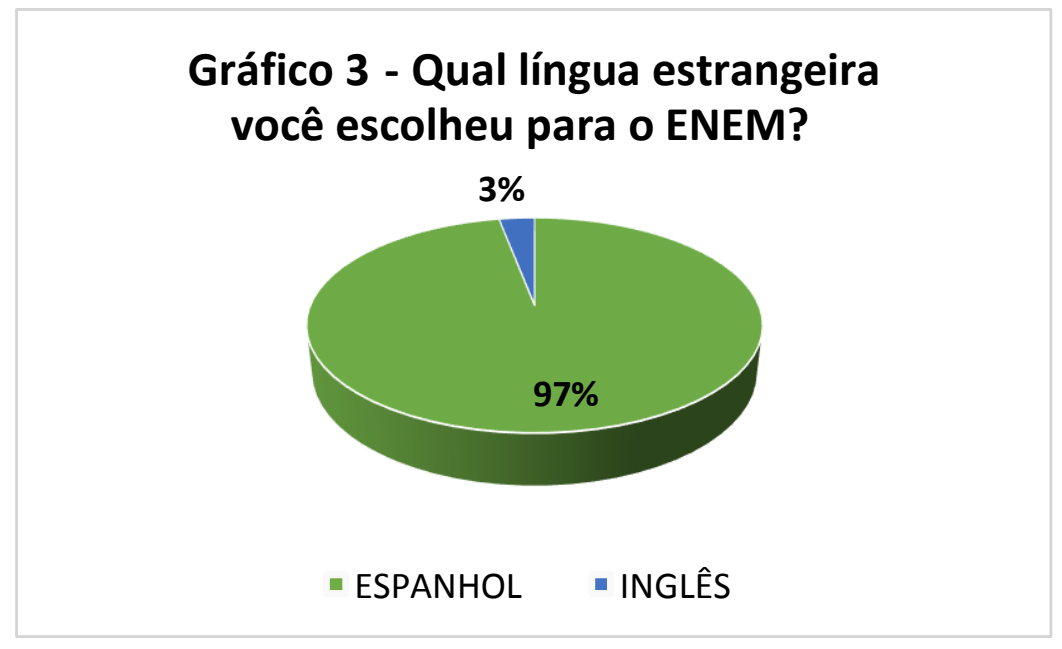

$\mathrm{Na}$ sequência da entrevista, a informante AF34 disse não ter justificativa para a opção do ENEM. Do total de alunos, $97 \%$ optaram pelo Espanhol e apenas 3\%, pelo Inglês. Nesse sentido, a professora da turma deu a seguinte justificativa:

O que leva os alunos a escolherem o Espanbol é o fato de ser uma lingua muito similar a nossa, e que acaba confundindo eles, porque apesar de ser similar, tem umas coisas que são parecidas, mas a traducão totalmente diferente o que pode levá-los a acabar errando as questões, mas o que os induze é isso, o fato do Espanhol parecer mais com nosso idioma. [...] o Inglês poucas palavras vão confundir, geralmente o aluno quando escolhe o inglês ou ele já tem o conbecimento da lingua, um público mínimo que já vem estudando, então na questão de confundir o Inglês com o Português é muito mais dificil.

Os alunos que optaram pelo Inglês justificaram que no ano anterior fizeram a prova com esta opção e se saíram melhor, uma vez que escutavam muita música em inglês, ou desde pequenos tinham vivência no idioma, e por se identificarem mais com este, fato que comprova o que a informante AF34 postulou. 


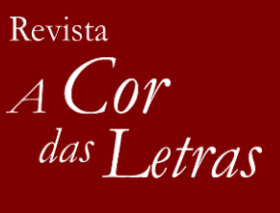

A partir da análise inicial das três perguntas já apresentadas, percebemos que os alunos estão carregados de formas de pensar e perpassam isso nos seus discursos. Desta forma, essa primeira parte de sondagem é terreno fértil para o que surge nos próximos gráficos. Sobre este aporte, Barcelos (2004a, p. 132) postula que “(...) as crenças não são apenas conceitos cognitivos, mas são 'socialmente construídas' sobre 'experiências e problemas', de nossa interação com o contexto e da nossa capacidade de refletir e pensar sobre o que nos cerca".

Aqui, verificamos também a presença das influências do convívio social, especificamente no que concerne à relação professor-aluno. Acerca disso, Barcelos (2001) comenta que as crenças dependem não só da experiência anterior de aprendizagem dos alunos mas também da abordagem de ensinar do professor. Isso se evidencia na fala de AF34, uma vez que esta também reforça uma facilidade atribuída ao Espanhol.

Em relação a este aspecto, apresentamos a seguir o Gráfico 4, que representa a justificativa do porquê dessa escolha, seguido das crenças que emergiram nos discursos dos aprendizes:

\section{Gráfico 4- Crenças norteadoras de escolha}

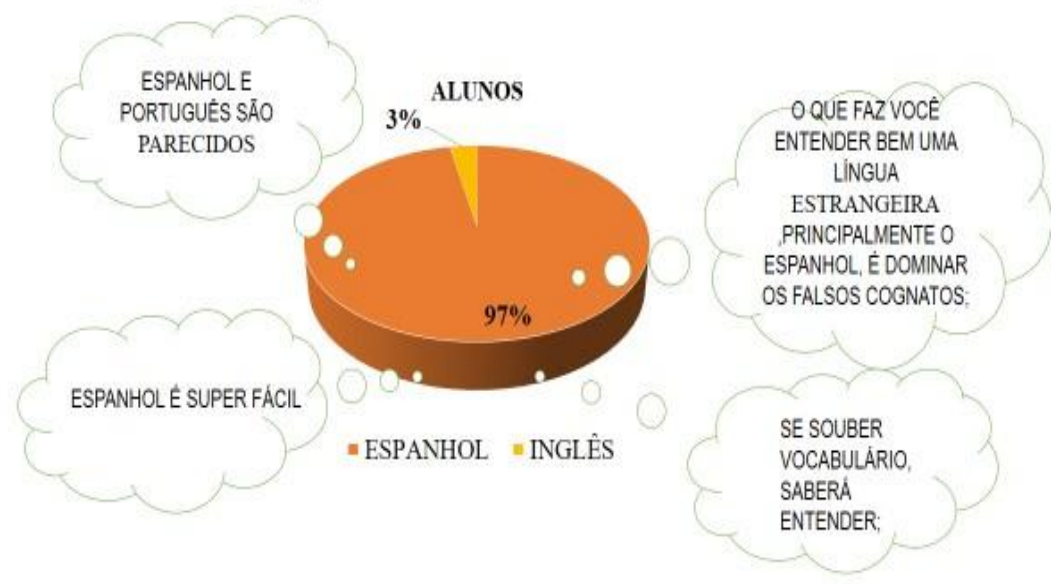

A primeira crença dominante foi a de facilidade e semelhança atribuída ao Espanhol:

Eu prefiro a língua espanhol mais pela associação a lingua portuguesa que é mais fácil de entender, e também é a lingua mais falada na América do Sul. (...) mais fácil de interpretar questões... (AM17)

Pelo meu conbecimento, o espanhol é mais fácil da gente entender, tem aquela questão das palavras ser um pouco parecida [... (BF16)

Para interpretar é mais fácil, pelo menos eu acho, por ter palavras que parecem, ser semelhantes, fica mais fácil de entender o geral que o texto está passando. (BF16) 


\section{das Letras}

É a que eu mais conheço e consigo traduzir mais palavras. (FM16)

É uma língua que se aproxima mais com o Português, e eu já tenho mais facilidade para traduq̨ir, ler.

$\mathrm{Na}$ fala dos informantes, percebe-se a crença linguística ancorada na origem dos idiomas, latim vulgar, e, consequentemente, na ideia de línguas irmãs, o que pressupõe facilidade. Segundo Goettenauer (2005, p. 63),

Espanhol e Português são duas línguas muito parecidas sim, têm a mesma origem e um repertório lexical comum bem extenso, mas há diferenças muito significativas: de entonação, de pronúncia, de estruturas, de expressões, de usos, de modos de expressar a realidade etc. $\mathrm{E}$ justamente por essas diferenças, torna-se difícil dominar satisfatoriamente a língua de Lorca e Neruda.

O gráfico a seguir exibe os resultados encontrados sobre essa crença:

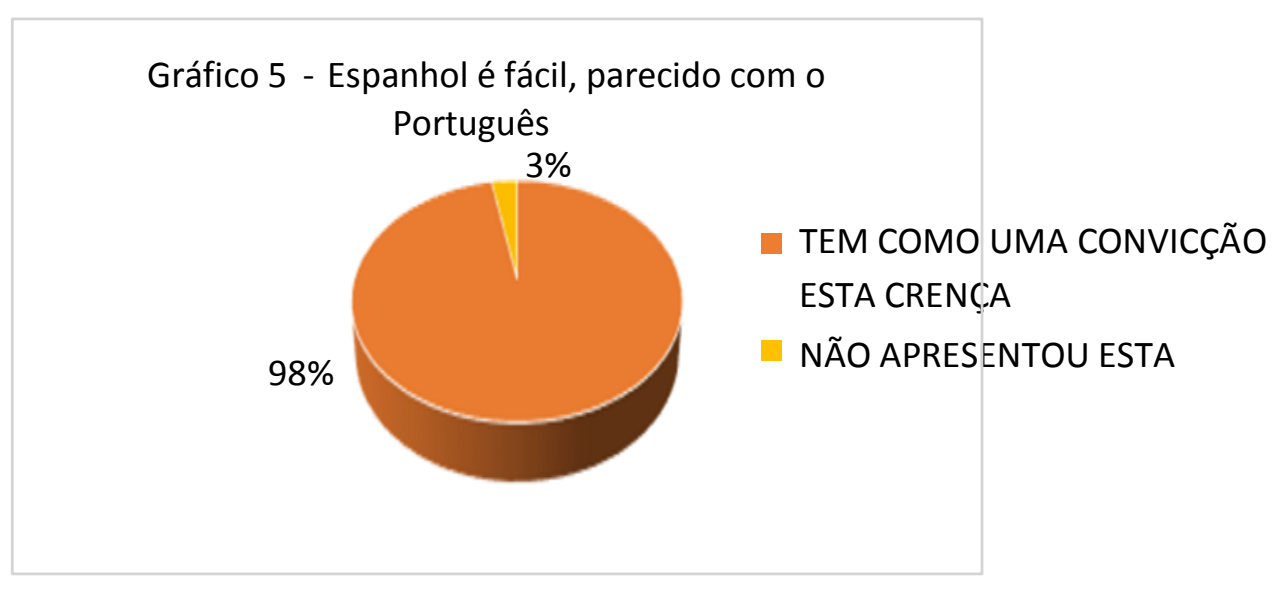

A segunda crença dominante é a de domínio vocabular, de que saber os falsos cognatos pressupõe dominar bem o que é necessário para ter sucesso no exame. 


\section{das Letras}

\section{Gráfico 6 - Domínio vocabular}

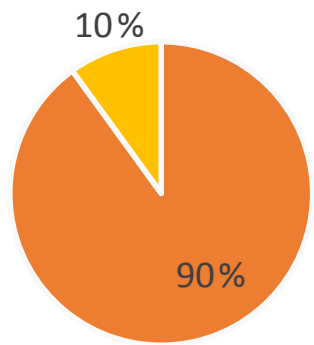

- CONVERGEM PARA A CRENÇA MENCIONADA

\section{- DIVERGEM/ E ALMEJAM O INGLÊS}

Merecem destaque algumas justificativas:

[...] E aprender mais o significado da lingua e não cair naqueles. ehh... Falsos cognatos. (AM17)

No Enem não cai tanto gramática, cai mais interpretação, então, eu acho assim, que o importante é você ler bastante textos em Espanhol, buscar ter um vocabulário muito grande de palavras para você não se enrolar ou não saber aquela palavra na hora da leitura. (SF16)

Ler bem os textos e também num cair naqueles falsos cognatos, conbecer muito sobre os falsos cognatos (...) já diminui a chance de errar. (IM16)

A questão de palavras e o duplo sentido que ela tem, tipo aparenta uma coisa e é outra, tipo esses minimos detalhes que a gente precisa aprender para se sair melhor. (NM17)

Sobre esse aspecto, Goettenauer (2005, p. 63) postula que:

Infelizmente ainda é comum ouvir dos alunos que o espanhol é muito fácil porque se parece muito com o português. Cria-se assim um falso preceito: para saber espanhol basta aprender o léxico, isto é, as palavras que são diferentes das empregadas em nossa língua. É necessário combater essa ideia errônea.

Os $10 \%$ de alunos que não convergiram para esta crença acreditam que focar no aprimoramento da interpretação do texto é o melhor caminho para lograr bons resultados.

Neste sentido, vemos a necessidade de mostrar aos alunos a importância de se observar as particularidades do idioma e também considerar a língua como um todo (estrutural, lexical, morfossintático, semântico etc.), para não incorrer no equívoco de 
produzir significações que nada tenham haver com a realidade do idioma.

\section{CONSIDERAÇÕES FINAIS}

No presente trabalho procurou-se fazer uma análise das crenças linguísticas que norteiam a escolha da Língua Espanhola para o ENEM. Concluiu-se com a pesquisa que os alunos acabam direcionando sua opção baseados na crença de proximidade existente entre sua língua materna, Português, e a língua estrangeira, Espanhol, além de acreditarem que, por serem próximas, se dominarem os falsos cognatos, conseguirão sempre bons resultados, reforçando a ideia de facilidade atribuída à Língua Espanhola. Os dados coletados através do questionário e da entrevista corroboram as colocações aqui citadas bem como vêm ao encontro de muitas outras pesquisas acerca de crenças.

Deste modo, intuímos que tenhamos atingido nosso objetivo, mas temos consciência de que uma única análise não abrangerá todas as possibilidades de investigação. Assim, acreditamos que iniciamos um diálogo que pode posteriormente ser ampliado e aguçar ainda mais o campo fértil de investigação de comportamentos linguísticos, com destaque para os estudos de crenças.

\section{REFERÊNCIAS}

BARCELOS, Ana Maria Ferreira. Cognição de professores e alunos: tendências recentes na pesquisa de crenças sobre ensino e aprendizagem de línguas. In: BARCELOS, Ana Maria Ferreira; ABRAHÃO, Maria Helena Vieira (Orgs). Crenças e ensino de línguas: foco no professor, no aluno e na formação de professores. Campinas: Pontes, 2006, p. 15-42. BARCELOS, Ana Maria Ferreira; KALAJA, P. Introduction: beliefs about SLA revisited. Special Issue of System, v. 39, p. 281-289, 2011.

GOETTENAUER, Elzimar. Espanhol: língua de encontros. In: SEDYCIAS, João (Org.). O ensino do espanhol no Brasil: passado, presente e futuro. São Paulo: Parábola, 2005. LABOV, William. The social stratification of English in New York City. Cambridge: Cambridge University Press, 1966.

MEILLET, Antoine. Linguistique historique et linguistique generale. Paris: Champion, 1965.

MORENO FERNÁNDEZ, Francisco. Principios de sociolingüistica y sociología del lenguaje. Barcelona: Editorial Ariel S. A., 1998.

OCEM. Orientações Curriculares do Ensino Médio. Brasília: MEC/SEMTEC. 2006.

PAJARES, F. M. Teachers beliefs and educational research: cleaning up a messy construct. Review of Educational Research, v. 62, n. 3, p. 307-332, 1992.

Recebido em: 28/02/2019

Aprovado em: 07/06/2019

Publicado em: 28/09/2019 